BULLETIN Bulletin hispanique

HISPANIQUE Université Michel de Montaigne Bordeaux

112-1| 2010

Actes du Colloque « langue, littérature, littéralité »

\title{
Rafael Alarcón Sierra, El mal poema de Manuel Machado: Una lírica moderna y dialógica
}

Biblioteca Nueva, Madrid, 2008

Almudena del Olmo Iturriarte

\section{OpenEdition}

\section{Journals}

Edición electrónica

URL: http://journals.openedition.org/bulletinhispanique/1203

DOI: 10.4000/bulletinhispanique.1203

ISSN: $1775-3821$

\section{Editor}

Presses universitaires de Bordeaux

Edición impresa

Fecha de publicación: 1 junio 2010

Paginación: 448-454

ISBN: 978-2-86781-692-5

ISSN: 0007-4640

\section{Referencia electrónica}

Almudena del Olmo Iturriarte, « Rafael Alarcón Sierra, El mal poema de Manuel Machado: Una lírica moderna y dialógica », Bulletin hispanique [En línea], 112-1 | 2010, Publicado el 04 enero 2013, consultado el 22 septiembre 2020. URL : http://journals.openedition.org/bulletinhispanique/1203 DOI : https://doi.org/10.4000/bulletinhispanique.1203 
F. Macchi souligne que, si l'accession des caciques à des charges jusque-là réservées aux créoles est une preuve de l'ouverture du régime, un bataillon d'Indiens vêtus à l'espagnole évite le tumulte de la foule et empêche que le public ne confonde la scénographie de la puissance ancienne et la ségrégation de l'époque moderne. La chercheuse complète son travail sur les reconstructions impériales en évoquant le drame inca Ollantay dont la datation est encore l'objet de débats. Elle reprend l'analyse de Martin Lienhard définissant l'Ollantay comme "expresión del predominio de la cultura oficial y la resistencia de unas culturas autóctonas marginadas que se nutren tanto de su pasado autónomo como de su historia en el marco colonial o semicolonial "(257). Comme pour les Lettres d'une Péruvienne, Macchi est attentive à la mise en scène de l'enfermement féminin et interprète la résolution de l'intrigue comme l'allégorie d'un futur modèle de communion sociale, dans le prolongement de la renaissance inca théorisée par John Rowe en 1954.

L'ouvrage de Fernanda Macchi s'achève sur l'Indépendance et la revendication de l'héritage inca lors du Congrès de Tucuman scellant la naissance des Provinces Unies du Rio de la Plata (1816), un saut chronologique et spatial qui explique peut-être la référence du titre à la seconde moitié du XVIII ${ }^{\mathrm{e}}$ siècle, postérieure à l'ensemble des " reconstructions impériales ", objets de cette étude hardie et minutieuse, mais qui prudemment n'aspire pas à l'exhaustivité sur un sujet encyclopédique.

\section{Isabelle TAUZIN-CASTELLANOS}

Rafael Alarcón Sierra, El mal poema de Manuel Machado:Una lírica moderna y dialógica. - Madrid, Editorial Biblioteca Nueva, 2008, 311 p. (Estudios críticos de literatura, 32) : índice onomástico. - ISBN 978-849742-748-7.

Rafael Alarcón Sierra es especialista principal en la obra de Manuel Machado. Es autor de numerosos artículos y de distintos estudios y ediciones cuya solvencia la garantiza siempre un amplio bagaje lector, que no se circunscribe únicamente a la tradición española, y una documentación de máxima especialización filológica. Sus monografías más relevantes sobre este tema son La poesía de Manuel Machado: Alma, Caprichos, El mal poema (estudio y edición critica) (1997), que fue base para su canónica edición de esas tres obras en el año 2000, y Entre el modernismo y la modernidad: la poesía de Manuel Machado (Alma y Caprichos) (1999). Por su parte, además de la edición citada, son muy interesantes por el material que incorporan las 
ediciones de Cuentos completos (1999) e Impresiones. El modernismo (Artículos, crónicas y reseñas, 1899-1909) (2000). A esta bibliografía de referencia se suma ahora, a los cien años de su publicación, El mal poema de Manuel Machado. Una lírica moderna y dialógica (2008).

En 1909 Manuel Machado publica uno de los libros más importantes del modernismo poético español: El mal poema. Según da cuenta Alarcón Sierra en su ensayo, el libro ve la luz en diciembre de ese ańo, aunque alguno de sus poemas data de 1903. En 1905 «El mal poema», integrado por siete textos, constituye la cuarta sección de Caprichos y en 1907 la Librería de Pueyo está anunciando ya la preparación de El mal poema como el próximo libro de Manuel Machado y su venta a tres pesetas. En efecto, la de 1909 es la primera edición de un libro al que el propio poeta parece conferirle una importancia especialmente relevante en su trayectoria. Al menos eso es lo que se deduce si se atiende a la dedicación que le brinda. En 1923 y 1924 se publican la segunda y la tercera edición de sendos conjuntos muy distintos aun siendo el mismo libro: El mal poema con diferentes adiciones y supresiones que modifican sustancialmente el resultado final. Es decir, la génesis, la composición y la revisión en sucesivas ediciones de El mal poema se demoran a lo largo de algo más de veinte años que coinciden con la maduración poética de su autor y con cambios de rumbo determinantes en la historia del panorama poético español. Es significativo que 1909 es también la fecha en que empiezan a detectarse en España los primeros síntomas de las vanguardias históricas con Ramón Gómez de la Serna al frente de la revista Prometeo.

De modo que, cuando menos, llama mucho la atención el lapso temporal transcurrido desde la primera edición hasta la segunda y tercera. Primero, porque referidos a la edad de Manuel Machado 1909, 1923 y 1924 nos llevan de los 35 a los 49 y 50 años de un Manuel Machado que pasa de la juventud a la madurez. Segundo, porque esos son los años que coinciden históricamente con momentos de cambios muy rápidos y en algunos casos determinantes para la poesía española: en 1908 se habla desde la revista Renacimiento del «simbolismo triunfante», toda una serie de poetas siguen aún la estela del modernismo en sus vertientes más variadas, pero, al mismo tiempo, los propios protagonistas del modernismo comienzan a poner en jaque los presupuestos modernistas. Es el caso de Antonio Machado o Juan Ramón Jiménez y también en cierto modo de Manuel Machado. A ello hay que sumar los primeros aldabonazos de las vanguardias históricas y las primeras propuestas de los poetas que integrarán el grupo del 27. En este contexto la revisión de El mal poema por parte de Manuel Machado en los años que median entre 1909 -y antes, considerando la procedencia y génesis 
de los textos, desde 1903 y 1905- y 1923 y 1924, los profundos cambios experimentados por el conjunto deben entenderse como la construcción de un proyecto poético «en marcha» que experimenta en el tiempo una revisión que da la talla de la exigente conciencia crítica a la que el autor somete la representación de su mundo poético y su lenguaje una vez que el modernismo de los primeros años del siglo ya se percibe como retórica.

El estudio de la procedencia de los textos y de la génesis de las sucesivas ediciones que presenta Rafael Alarcón permite considerar El mal poema no sólo como un librito más de poesías con las que en 1909 Manuel Machado, ya desde el título, pretenda epatar, o escandalizar, o simplemente salirse por la tangente de la estética triunfante del simbolismo interior. Por cierto, que eso mismo y por esos mismos años lo estaba intentando su hermano Antonio, aunque de forma muy distinta, apuntando hacia los universales del sentimiento colectivo con una poesía entendida como palabra en el tiempo histórico. El mal poema supone todo un proyecto ético-estético abierto a lo largo de más de veinte ańos y haciéndose gracias a un proceso permanente de indagación y, sobre todo, de cuestionamiento de la propia coyuntura vital y de muchos aspectos poéticos. No puede olvidarse que cuando Manuel Machado publica El mal poema atraviesa un momento complicado de su vida -parece llegado el momento de sentar la cabeza después de una juventud bohemia y aborrascada, el núcleo de la "gente nueva» se está disolviendo, su hermano Antonio no está con él...-y, también, por un momento de desencanto provocado por el panorama literario. Porque a esas alturas a Manuel Machado, entre unos y otros, ya le han criticado casi todo. Y siendo así parece querer dar razones que justifiquen las nuevas críticas desde el mismo título del conjunto para, de paso, disolver las barreras entre vida y poesía. La mala vida sólo puede dar como resultado poemas que su propio autor presenta como malos desde la ironía, desde la socarronería, pero también desde el descrédito de quien sabe lo que hay.

La poesía ya no puede seguir entendiéndose como una construcción artificiosa de la vida, como un paraíso artificial para el alma o como un capricho estético. Muy al contrario, en proyección de dentro a fuera, la poesía entraña todo un proceso de desenmascaramiento en el que ya no sirven las ańagazas estéticas. Eso es lo que dicen los primeros versos del «Retrato» que abre El mal poema: «Ésta es mi cara y ésta es mi alma. Leed:/ Unos ojos de hastío y una boca de sed.../ Lo demás... Nada... Vida... Cosas... Lo que se sabe...» $\mathrm{Y}$ en ese desenmascaramiento que, entre otras cosas, lleva el ritmo del verso a los registros más coloquiales y al argot, puesto que ya no sirve ni siquiera la máscara del lenguaje en su prestigioso registro poético, se cifra la radical modernidad de El mal poema, trascendiendo en el tiempo la validez 
de su propuesta para el modernismo histórico.

Rafael Alarcón, además de explicar con rigor y exhaustiva documentación el complejo proceso de génesis, composición y publicación de $E l$ mal poema en sus sucesivas ediciones - un proceso ya esbozado, por otra parte, en su edición del libro- vuelve sobre los aspectos que le confieren al conjunto esa modernidad y su vigencia: la creación de un personaje poético, la consideración de la poesía de experiencia o la heterogeneidad de los registros:

mezcla lo alto con lo bajo, lo literario con lo extraliterario, lo «poético» con lo cotidiano, lo «lírico» con lo prosaico, lo retórico con lo coloquial, la palabra "pura» con la ajena -plurilingüismo-, lo escrito con lo oral -el argot, la frase hecha, el refrán, el giro conversacional, las muletillas léxicas...-, el ritmo noble con la rima fácil, con el soniquete de la canción callejera y villonesca, del cante y lo aflamencado. En definitiva, mezcla los géneros, los estilos, los registros, los recursos, las voces y los ritmos (p. 31).

Señalar estos aspectos no resulta novedoso en sí, pero sí lo es aplicar un andamiaje teórico que Alarcón toma de Mijaíl Bajtín y que hace piedra angular del concepto de "dialogismo» aplicado a la "variante renovadora de la literatura, que tensa al máximo la palabra propia teniendo en cuenta desde dentro la palabra ajena» (p. 33).

En este marco teórico Alarcón inserta El mal poema para revisar las características de su modernidad a la luz de los rasgos genéricos de las obras consideradas dialógicas dentro del "llamado dominio de lo cómico-serio» (p. 34). Porque como afirmación general es cierto que Manuel Machado habla en ocasiones de cosas muy serias sin que su registro expresivo o su ideología, en el sentido más amplio del término, parezca tomárselas en serio del todo. Los tres rasgos que se aplican a El mal poema, tal como los plantea Alarcón, son los siguientes: «el tratamiento de la realidad viva y cotidiana, su fundamentación en la propia experiencia y en la libre invención, y (...) la heterogeneidad de estilos y voces» (pp. 35-36). Tres rasgos que, en lo esencial, coinciden con lo que Rafael Cansinos Asséns denominara «literatura de arrabal» al vincular las formas del pensamiento y del arte con las maneras de representación de lo urbano. En definitiva, el concepto de literatura dialógica le sirve al autor para iluminar novedosamente esa difuminación de límites entre lo ético y lo estético en El mal poema, que es el puntal de su vigencia presente: «Esta íntima fusión de lo ético y lo estético, de la experiencia personal del sujeto y de su expresión ideológica, en la obra artística, es, sin duda, la máxima potencialidad de la literatura dialógica» (p. 37). 
Quizás por esta modernidad El mal poema no se entendió en su tiempo. También de la recepción crítica del libro proporciona un seguimiento sumamente interesante Rafael Alarcón. En ese rastreo hay varias cuestiones de especial interés. En primer lugar, resulta muy llamativa la nueva vuelta de tuerca, irónica en extremo -por si la ironía y el sarcasmo que rezuman de $E l$ malpoema no fueran suficientes-, que da Manuel Machado en la justificación de su libro contenida en la carta abierta dirigida a Juan Ramón Jiménez. Las explicaciones ofrecidas en 1913 al joven Juan -pero no sólo porque de ser así la carta abría sido cerrada, obviamente- apuntan al centro de la diana de ese nuevo desenmascaramiento que Manuel Machado le exige a la poesía, una forma de entender la práctica poética como ficción que destile vida de verdad, no filigrana artística enajenada o desafecta:

La vida, Juan, a despecho de nuestras canciones, es una cosa bastante pesada y difícil. (...) Conozco la delicadeza de tu espíritu y sé que te chocan ciertas trivialidades y malsonancias de que por desgracia está lleno nuestro vivir. Pero creo haberte dicho en mi descargo que, no sólo se canta lo que se ama, sino lo que se odia más cordialmente. En suma, todo lo que de veras nos impresiona (p. 46).

En segundo lugar, es llamativo el silencio casi absoluto con que los críticos de mayor prestigio reciben el nuevo libro de Manuel Machado en el momento de su publicación. En 1909 se refiere a El mal poema Amado Nervo, amigo de Machado, en la Revista Moderna de México. Y poco más, excepción hecha de la acertadísima valoración de Andrenio contenida en un artículo de Nuevo Mundo, pero que data de 1915. Mientras tanto, sí surgen voces que lo denostan, como la de José María Salaverría en 1910 desde el $A B C$, que lo califica de "peste literaria profundamente inmoral», porque se pregunta el crítico en cuestión: «con estos sentimientos, ¡es posible hacer un pueblo fuerte y civilizado...?» (p. 55). Paradójicamente, Salaverría afirma también: «Esto es hermoso, efectivamente, es sublime y es poético y noble.» Esta doble consideración, que a pesar de reconocer la belleza poética de $E l$ mal poema lo condena a la quema por ser moralmente pernicioso, nos pone sobre aviso: con la raza hemos topado.

Desde esta perspectiva ya no sorprende tanto la ambivalencia del propio Manuel Machado frente a este libro por el que en algún momento reconoce su debilidad, mientras que en 1940, en su discurso de ingreso a la Real Academia Española, asegura sentir vergüenza. Claro está que a esas alturas de la historia la raza y el caudillo, al que entre otras cosas el poeta dedicara algún poema encomiástico, ponían tasa a las conciencias civiles y poéticas, 
y las vergüenzas y los arrepentimientos marcaban la menor de las carestías. Y quizás fue por esos ańos por los que Manuel Machado perdió el tren de la historia. A partir de aquí la recepción de este poeta, en bloque y sin distingos en su larga trayectoria poética, parece improcedente. Los críticos y filólogos adeptos al régimen no pudieron proponerlo como ejemplo en sus veinticinco años de producción inicial, los que llevan de Alma a El mal poema en sus tres ediciones hasta 1924, porque Manuel Machado no sólo era decadente, sino también inmoral y nada edificante para la raza. Y la otra media Espańa, con el corazón helado, encontró en su hermano Antonio el más alto ejemplo ético y de dignidad moral.

La poesía de Manuel Machado, y en particular El mal poema, comienza a ser recuperada por algunos poetas del grupo del 50 como Jaime Gil de Biedma y Gabriel Ferrater y tiene un peso importante en voces muy dispares del panorama poético actual y que representan tendencias bien distintas. Es el caso de Miguel d'Ors y de Andrés Trapiello, por mencionar dos poetas que son, además, especialista en la obra de Manuel Machado el primero y editor de una de las antologías poéticas más asequibles en su día el segundo. Pero junto a ellos puede nombrarse a Luis Antonio de Villena, Fernando Ortiz, Carlos Marzal, Felipe Benítez Reyes o Javier Salvago. Y a pesar de todo, la crítica y los docentes más academicistas, por unas razones, y la crítica y los docentes más progresistas, por otras, parecen todavía mirar de soslayo la poesía de Manuel Machado. Desterrado de las aulas y de los planes de estudio, dentro del sistema educativo Manuel Machado sólo se lee en las universidades en el mejor de los casos y es casi un desconocido para el lector medio de poesía. Uno de los últimos homenajes de reivindicación crítica se lo brindó la revista Ínsula en un número coordinado, precisamente, por Alarcón y con un significativo título tomado de "Adelfos», el autorretrato con que se abre Alma: «Gloria... ¡la que me deben!», pero en conmemoración del cincuentenario de su muerte el número data ya de 1997. Y este año, 2009, cuando ahora hace cien años de la primera edición de El mal poema, en un colectivo tan aficionado a las conmemoraciones como lo es el de los filólogos, no parece que los homenajes hayan llegado muy lejos.

En otro orden de cosas, sucede a menudo que cuando los críticos filológicos hablan sobre poesía o sobre la poesía de un determinado autor, curiosamente, pasan por encima de los poemas concretos como si éstos fueran mero accidente. No es el caso de Alarcón Sierra cuya aportación más valiosa en su último trabajo radica en la profundización individualizada en todos y cada uno de los textos que en sus ediciones sucesivas van apareciendo o desapareciendo de El mal poema. Se trata de comentarios textuales pormenorizados y sugestivos por las asociaciones comparatistas que 
establecen -demostrando un conocimiento imprescindible de la tradición poética francesa asimilada desde sus inicios literarios por Manuel Machadoy que abren nuevas posibilidades de indagación muy distintas y amplias. Para los filólogos alcanforados que trivializan el trabajo de quienes nos dedicamos al estudio y edición de la poesía contemporánea, el de Rafael Alarcón Sierra es uno de los mejores ejemplos que cabe proponerse como de máxima especialización, tanta como la requerida para estudiar y anotar textos medievales o del Siglo de Oro.

\section{BIBLIOGRAFÍA CITADA}

Rafael Alarcón Sierra, La poesía de Manuel Machado: Alma, Caprichos, El mal poema (estudio y edición crítica), Zaragoza, Prensas Universitarias de Zaragoza (Serie Microfichas), 1997.

- (ed.) (1997). “Gloria... jla que me deben!”, Manuel Machado (1947-1997)», Insula, 608-609.

- (ed.) (1999). Manuel Machado, Cuentos completos, Madrid, Editorial Clan.

- (1999). Entre el modernismo y la modernidad: la poesía de Manuel Machado (Alma y Caprichos), Sevilla, Diputación Provincial de Sevilla.

- (ed.) (2000). Manuel Machado, Alma. Caprichos. El mal poema, Madrid, Castalia.

- (ed.) (2000). Manuel Machado, Impresiones. El modernismo (Artículos, crónicas y reseñas, 1899-1909), Valencia, Pre-Textos.

- (2008). El mal poema de Manuel Machado. Una lírica moderna y dialógica, Madrid, Biblioteca Nueva.

\section{Almudena del OLMO ITURRIARTE}

Rafael Alarcón Sierra, Luis Felipe Vivanco: contemplación y entrega, Madrid, Ayuntamiento de Madrid, 2007.

En su último libro Luis Felipe Vivanco: contemplación y entrega (2007), editado por la Imprenta Artesanal del Ayuntamiento de Madrid en una colección dirigida por Mario Hernández, Rafael Alarcón Sierra (director del Departamento de Filología Española, Universidad de Jaén) nos revela la trayectoria vital y poética de este poeta casi olvidado en las letras españolas. Como va siendo común con Alarcón Sierra -autor de las monografías Entre el modernismo y la modernidad: la poesía de Manuel Machado (Alma y Caprichos) (1999, Premio Archivo Hispalense) y Juan Ramón Jiménez. 